\title{
Resenha de DE-LORENZI, Felipe da Costa. Justiça negociada e fundamentos do direito penal: pressupostos e limites materiais para os acordos sobre a sentença. São Paulo: Marcial Pons, 2020
}

\section{Ana Claudia Grossi}

A monografia de De-Lorenzi consiste na sua tese de Doutorado, elaborada perante o Programa de Pós-Graduação em Direito da Pontifícia Universidade Católica do Rio Grande do Sul, sob a orientação do Professor Dr. Fabio D'Avila, com período de investigação na Universidade Humboldt de Berlim, na cátedra do Professor Dr. Luís Greco.

O convidativo prefácio elaborado por Greco, que fala por si só, a atualidade do tema e o ângulo escolhido pelo autor - ainda pouco explorado no cenário nacional - revelam o peso da contribuição de De-Lorenzi para o processo penal brasileiro.

A crescente adoção de práticas negociais pelo legislador pátrio sinaliza a aproximação do processo penal brasileiro ao modelo da common law, em especial o estadunidense. Contudo, o movimento tem sido realizado sem maiores reflexões acerca do impacto estrutural dessa adoção para as bases do nosso direito, filiado à tradição continental, romano-germânica. Tal tendência político-criminal não é exclusiva do legislador brasileiro, o que Schünemann descreveu anteriormente como "prenúncio da derrocada da cultura jurídica alemã"1. 
Diante dessa realidade, doutrina e jurisprudência pátrias têm se ocupado primordialmente dos contornos e desafios práticos que a adoção dos mecanismos negociais trouxe para o cotidiano forense, centrando esforços na tentativa de delimitação dos institutos e no equilíbrio das forças entre os sujeitos processuais. Menor atenção tem sido dedicada a reflexões principiológicas e sistêmicas, que são especialmente importantes no contexto do acordo sobre a sentença (barganha), que possui consequências jurídicas mais severas do que as demais figuras consensuais. No entanto, tais reflexões se fazem indispensáveis, já que a introdução dos acordos sobre a sentença no ordenamento jurídico brasileiro tem sido objeto de inúmeras propostas que tramitam há anos nas casas legislativas, especialmente o PL 8.045/2010 - Projeto de Novo Código de Processo Penal.

Essa é justamente a preocupação de De-Lorenzi, por mim compartilhada², brilhantemente investigada e aprofundada em sua obra. $\mathrm{O}$ autor parte de uma vasta leitura, revelada por uma bibliografia profunda, com influência de renomada doutrina nacional e estrangeira, sem desconsiderar, ainda, estatísticas oficiais, dados de segurança pública, jurisprudência e a atividade legislativa sobre o tema, inclusive com um anexo dedicado aos projetos de lei a respeito do acordo sobre a sentença no Brasil $^{3}$.

De-Lorenzi estrutura a sua obra em torno de quatro capítulos: 1. Introdução; 2. Aproximações ao fenômeno dos acordos sobre a sentença; 3. Acordos sobre a sentença e fundamentos do direito penal; e 4. Conclusão.

Inicialmente, o autor delimita, com o rigor científico que se espera de uma tese doutoral, o que seria "justiça negociada", por meio de uma análise terminológica, da identificação dos elementos que a comporiam e da sua distinção de institutos similares. Conclui, assim, que justiças negociada ou consensual seriam sinônimos, que descreveriam institutos que permitem um acordo entre órgãos públicos de persecução e investigado, durante o processo penal (por adesão a uma proposta ou concessões mútuas), com o objetivo de garantir um benefício ao investigado/réu, em troca de renúncia ao exercício integral de seus direitos processuais, para dar efetividade e eficiência ao sistema penal ${ }^{4}$.

GROSSI, Ana Claudia. Pode o acordo ser uma solução para os problemas da morosidade e sobrecarga da Justiça? Subsídios para um debate, a partir da experiência alemã. Revista Brasileira de Ciências Criminais, São Paulo, v. 114, p. $133-171,2015$. 
A partir daí, entre todos os fenômenos abarcados pelo termo "justiça negociada", na qual se incluem no Brasil a transação penal (Lei no 9.099/1995), a colaboração premiada (Lei $\mathrm{n}^{\mathrm{0}}$ 12.850/2013) e os acordos de não persecução penal (Lei no 13.964/2019), o autor foca seu estudo especificamente nas negociações sobre a sentença, nas quais há imposição de pena, em sentido material, geralmente privativa de liberdade ${ }^{5}$. De-Lorenzi justifica essa opção pelo fato de que a imposição de uma pena corporal, por configurar a intervenção mais severa nos direitos fundamentais do indivíduo - ao menos em teoria - seria um "mal qualificado" ${ }^{\prime \prime}$, que exigiria maior legitimação do que outras sanções jurídicas, falando em uma "especial necessidade de justificação"7.

Considerando os acordos sobre a sentença penal como uma alternativa à instrução processual, eles se caracterizariam, para o autor, fundamentalmente: a) pela supressão ou redução substancial da fase de instrução; b) pela concessão de um benefício ao réu, em troca de uma manifestação voluntária sua, que servirá de fundamento para a sentença; c) pelo fato de o acordo possuir os mesmos efeitos de uma sentença condenatória ou equiparáveis a ela; d) pela possibilidade de efetiva aplicação da pena privativa de liberdade; e e) pela possibilidade de sua aplicação a crime de média ou alta gravidade ${ }^{8}$.

Diante da ausência de norma em vigor no Brasil sobre o tema - ainda em discussão pelo Poder Legislativo -, De-Lorenzi parte da experiência do direito comparado para a apreensão do núcleo essencial de um acordo sobre a sentença. Nesse ponto, há que se destacar a bela pesquisa feita pelo autor, que aborda detalhadamente e de forma sistematizada os principais modelos de acordos sobre a sentença de que se tem conhecimento: o plea bargaining, nos Estados Unidos; a Absprache, na Alemanha9; o pattegiamento, na Itália; e a conformidad, na Espanha $^{10}$. O autor faz um breve histórico da implementação do acordo em cada um desses ordenamentos, com uma síntese das características do processo penal de cada país, pontuando os principais aspectos de cada modalidade de acordo, como a possibilidade de negociação sobre fatos, imputações e penas, consequências jurídicas, controle judicial, vinculação do Judiciário aos termos do acordo e forma de determinação dos benefícios. Ao final, traça, de forma organizada, o 
que chama de "uma comparação indutiva" entre os modelos anteriormente abordados, amarrando-os pelas suas distinções e características comuns ${ }^{11}$.

Partindo do pressuposto de que os desafios acerca da compatibilização de uma sentença negocial com o sistema jurídico penal originam-se do antagonismo de interesses individuais e coletivos próprios a esse sistema ${ }^{12}$, o autor organiza, de forma interessante e original, o ponto central do debate travado em torno de dois grandes eixos: a proteção individual frente ao poder punitivo e o interesse da coletividade na punição de crimes $^{13}$.

Os interesses coletivos são representados pela necessidade de proteção penal de determinados bens jurídicos mais caros à sociedade, por meio da criminalização e da gradação da punição. Eles se relacionariam, para o autor, portanto, com o próprio conceito material de crime, com a função da norma penal e com as teorias da pena. Diante da severidade da interferência penal, os interesses coletivos exigiriam um maior ônus de justificação e poderiam ser relativizados frente ao caso concreto ${ }^{14}$. Os direitos individuais, por sua vez, limitariam o poder punitivo estatal, fundamentando a punição para o próprio indivíduo, que cruzou a fronteira da legalidade, relacionando-se diretamente aos princípios da legalidade e culpabilidade. Representariam, entretanto, limites instransponíveis do direito penal, "restrições deontológicas" (remetendo a Greco) ${ }^{15}$.

Assim, o autor divide o escopo de seu estudo em dois grandes problemas: um primário, que seria a compatibilidade em si dos acordos sobre a sentença com os princípios da culpabilidade, da legalidade, com as funções das normas penais e as teorias da pena; e um secundário, acerca dos requisitos mínimos necessários, caso se prossiga com a incorporação dos acordos sobre a sentença no Brasil.

De-Lorenzi parte da frequente crítica de que o acordo sobre a sentença traria um descompasso entre a punição negociada e os tipos e as sanções estabelecidos pela legislação penal, por meio da disposição sobre a aplicação da lei penal no processo ${ }^{16}$.

Em sua investigação, o autor adota uma concepção unilateral do princípio da legalidade, centrada em um único papel, de garantia fundamental e limite ao 
poder punitivo estatal, visão que se justificaria pelo fato de as vedações à analogia e retroatividade em matéria penal se aplicarem apenas em benefício do réu no processo penal, o que demonstraria a prevalência dos direitos individuais do acusado frente aos interesses coletivos na punição ${ }^{17}$. Assim, inexistiria incompatibilidade, por si só, entre o acordo sobre a sentença e o princípio da legalidade simplesmente pela não aplicação de uma norma ou sanção previstas em lei a um fato, já que a legalidade vedaria apenas a punição por crimes e sanções mais severas do que a determinada legalmente, desde que esse espaço de discricionariedade e oportunidade para afastamento dos marcos legais se desse por igual previsão legal ${ }^{18}$.

Entretanto, essa previsão legal deveria respeitar as quatro dimensões do princípio da legalidade: a) reserva de lei formal ou proibição de direito consuetudinário (lex scripta); b) mandado de determinação ou taxatividade da lei penal (lex certa); c) proibição de analogia e extensão/restrição teleológica da lei penal em prejuízo do réu (lex stricta); d) proibição da retroatividade da lei penal mais gravosa (lex praevia) ${ }^{19}$.

Para o atendimento a todas essas implicações se exigiria: a) que a previsão abstrata dos acordos sobre a sentença ocorresse por meio de uma lei federal em sentido estrito, fruto da legitimidade dos representantes eleitos, sendo insuficiente a sua implantação por negociações processuais praeter legem ou resoluções de órgãos da Administração Pública ou Judiciária ${ }^{20}$; b) a necessidade de um regramento detalhado dos acordos sobre a sentença, com critérios passíveis de conhecimento ex ante e controláveis ex post ${ }^{21}$, que incluíssem necessariamente o objeto, as hipóteses de admissão, os benefícios possíveis de serem concedidos, as suas consequências e o papel do controle judicial22; c) a impossibilidade de ampliação do sentido literal do acordo sobre a sentença em desfavor do réu, podendo ocorrer em seu favor ${ }^{23}$, nos limites do sentido literal possível e da ratio legis ${ }^{24}$; d) a aplicação das alterações legislativas sobre o acordo prejudiciais ao réu apenas a crimes posteriores à sua promulgação, ao mesmo tempo em que as 
mais favoráveis (lex melior) seriam aplicáveis imediatamente, alcançando infrações anteriores ${ }^{25}$.

Entretanto, ainda que houvesse uma detalhada regulamentação sobre a matéria, De-Lorenzi demonstra preocupação com o risco de desnaturação do instituto pela prática forense, a exemplo do que ocorreu na Alemanha ${ }^{26}$, o que levaria ao grave risco de decisões arbitrárias e condenações injustas, pelo que conclui que os acordos sobre a sentença não deveriam ser incorporados ao ordenamento brasileiro ${ }^{27}$.

O princípio da culpabilidade, ao impor que uma pena só possa ser aplicada a quem tenha comprovadamente cometido uma conduta típica e apenas na medida de sua culpabilidade, traz severas implicações teóricas aos acordos sobre a sentença. Daí se extraem as duas maiores críticas aos acordos sobre a sentença, tratadas por De-Lorenzi: a) a possibilidade de aplicação de uma pena em desacordo com a culpabilidade do autor; e b) a possibilidade de aplicação de pena a um inocente.

Para o enfrentamento dessa questão, a exemplo do que adotado em relação ao princípio da legalidade, De-Lorenzi assume uma dimensão estritamente unilateral do princípio da culpabilidade, visto unicamente como garantia individual, por meio da qual a culpabilidade é um pressuposto necessário, mas não suficiente para a punição, ou seja, nenhuma pena poderia ser aplicada sem constatação de culpabilidade, mas a sua existência, por si só, não obrigaria o Estado a punir ${ }^{28}$, já que a pena só se justificaria quando socialmente útil e não como uma "compensação da culpabilidade", com qualquer fundamentação metafísica ${ }^{29}$. Tal visão, fundada na proteção do indivíduo frente aos excessos do poder punitivo em um Estado liberal, sobrepõe a dignidade do indivíduo aos interesses da comunidade, preventivos ou utilitaristas.

Em consonância com a linha de raciocínio adotada, De-Lorenzi esclarece que, além de o acordo sobre a sentença não poder evidentemente implicar na aplicação de uma pena que exceda a margem superior merecida pelo autor em virtude de seu comportamento, a vedação de pena superior à culpabilidade implicaria também na vedação ao aumento de pena pela simples recusa do acusado 
em realizar o acordo, bem como na proibição de ameaça de uma pena maior que a adequada (overcharging), pressionando o acusado à aceitação do acor$\mathrm{do}^{30}$. De outro lado, para o autor, essa perspectiva individualista da culpabilidade permitiria até mesmo a aplicação de uma pena inferior à pena proporcional à responsabilidade subjetiva, já que mais benéfica ao indivíduo, sendo que o objetivo do princípio da culpabilidade seria apenas a sua proteção individual (não instrumentalização) ${ }^{31}$.

A redução do procedimento penal objetivada pelo acordo sobre a sentença, no intuito de garantir maior eficiência e agilidade ao processo, torna dispensável a fase de instrução, na qual a verdade seria investigada, atribuindo-se força absoluta à declaração do réu. Intuitivamente já se percebe o risco de maior espaço para condenações injustas, já que a declaração do réu não é necessariamente fidedigna, sendo, muitas vezes, o resultado de uma simples matemática de probabilidades (aceita-se voluntariamente uma pena injusta menor frente ao risco palpável de uma condenação ainda mais injusta a uma pena maior). Tal fato é notório no Direito estadunidense, e a perplexidade gerada por esse estado de coisas tem resultado na sua abordagem até mesmo fora dos limites jurídicos e acadêmicos, em obras cinematográficas e literárias ${ }^{32}$.

Para De-Lorenzi, a partir de sua visão individualista sobre a culpabilidade, o fato de o procedimento abreviado impedir a investigação da verdade não representaria um problema para a compatibilidade do acordo sobre a sentença com o princípio da culpabilidade em si, remetendo, na realidade, ao interesse coletivo de que o crime seja punido e com pena adequada, com finalidades preventivas ${ }^{33}$. Como o princípio da culpabilidade buscaria exclusivamente a proteção do indivíduo, a busca da verdade seria exigida apenas em seu benefício, para evitar que fosse punido na ausência de culpabilidade ou por uma pena superior à devida

32 A título de ilustração, podemos citar o famoso caso de Korey Wise, Kevin Richardson, Yusef Salaam, Antron McCray e Raymond Santana, conhecidos como "Os cinco do Central Park", retratado em The Central Park Five (2012). Outros inúmeros casos de condenações injustas com base em falsas confissões podem ser visualizados no site do Center of Wrongfull Convictions da Universidade Northwestern (Disponível em: https://www.law.northwestern.edu/ legalclinic/wrongfulconvictions/exonerations/. Acesso em: 7 out. 2021), bem como no site do The National Registry of Exonerations da Michigan Law School (Disponível em: https://www.law.umich.edu/special/exoneration/Pages/ browse.aspx. Acesso em: 7 out. 2021). 
pela sua responsabilidade, sendo lícito, por outro lado, abrir mão da verdade para absolver ou aplicar pena mais branda que a merecida pelo réu ${ }^{34}$.

Registra-se que a posição não é unânime ${ }^{35}$, e, embora possua o êxito de salvaguardar satisfatoriamente as garantias individuais frente ao acordo sobre a sentença, atendendo à inegável dimensão de garantia individual do princípio da culpabilidade, desperta alguma reflexão no que tange à existência de uma eventual dimensão constitucional do princípio da culpabilidade como fator legitimador da própria aplicação da pena pelo Estado, alcançável pela busca da verdade no processo, como a própria afirmação da existência de um Estado de Direito.

Não escapa ao autor, entretanto, que o acordo sobre a sentença, ao suprimir a fase de instrução, obviamente reduz também a base fática exigida para a condenação, ameaçando fortemente as exigências processuais do princípio da culpabilidade e aumentando o risco de punição de inocentes, razão que leva De-Lorenzi novamente a não recomendar a sua incorporação no ordenamento pátrio. Caso isso ocorra, defende que seria necessária a adoção de exigências mínimas irrenunciáveis de suporte probatório para a constatação da culpabilidade e cautelas adicionais para a proteção do réu no procedimento simplificado de acordo $^{36}$.

Nesse sentido, o autor passa a analisar o tipo de manifestação do réu que seria exigida como veículo para o acordo, em respeito ao princípio da culpabilidade, abordando as mais conhecidas: a) a aceitação da pena; b) a admissão formal de culpabilidade; e c) a confissão ${ }^{37}$. Ele conclui que a aceitação da pena, comum nos Estados Unidos, na Espanha e na Itália, e a admissão formal de culpabilidade, que ocorre, por exemplo, no guilty plea estadunidense, não atenderiam às exigências do princípio da culpabilidade, já que inexistiria qualquer suporte probatório para a afirmação da responsabilidade do réu. Por sua vez, a confissão do réu no âmbito do acordo para a sentença, utilizada na Absprache alemã, possuiria dificuldades inerentes a uma confissão obtida mediante a oferta de redução da pena, que poderia assumir caráter pragmático, permitindo uma falsa assunção de culpa.

35 FRISCH, Wolfgang. Schuldprinzip und Absprachen. In: SAFFERLING, Cristoph; KETT-STRAUB, Gabriele; JÄGER, 2017. p. 685-702. p. 686 e 687. 
No entanto, por se tratar de uma prova, De-Lorenzi considera que a confissão diante de uma autoridade judicial poderia oferecer suporte fático para a constatação de culpabilidade, contanto que munida de algumas características, como o detalhamento da confissão, o prévio esclarecimento do acusado, a sua realização em audiência pública e o acompanhamento por defensor ${ }^{38}$. Entende, ainda, que o juiz deveria informar ao réu as consequências do acordo, aferir a sua voluntariedade e, evidentemente, não poderia participar da elaboração do acordo, podendo solicitar diligências e fazer questionamentos para esclarecer os fatos, rejeitando o acordo em caso de não convencimento da culpabilidade do réu. O registro audiovisual seria fortemente recomendado, para posterior controle do acordo pelas instâncias superiores ${ }^{39}$. Além disso, defende que o juiz deveria, apesar de um acordo, averiguar a inexistência de alguma "causa de não punibilidade", passível de absolvição de ofício, inspirada no modelo italiano ${ }^{40}$.

A compatibilização do acordo sobre a sentença realizado pela confissão do acusado com o princípio da culpabilidade, por meio da adoção das mencionadas cautelas, que apostam especialmente no controle judicial, é louvável. No entanto, não se pode deixar de refletir se a proposta do autor confia demasiadamente na figura do juiz e não resolve o problema da inexistência da oferta de provas, com a qual a autoridade judicial poderia confrontar a versão do acusado, corroborada pelo Ministério Público. Talvez, estar-se-ia mais próximo de uma conferência dos pressupostos formais para a homologação do acordo (voluntariedade, esclarecimento, etc.), do que de uma validação da versão apresentada, necessária ao cumprimento do nulla poena sine culpa, que, sem instrução probatória, se torna impossível ${ }^{41}$.

Acerca do caráter coativo dos acordos sobre a sentença, De-Lorenzi, com base na vasta jurisprudência estadunidense ${ }^{42}$, trata dos riscos de injustiça e da coação do acusado à aceitação do acordo, em uma análise de probabilidade e perdas e ganhos, a partir de um suposto consentimento livre e voluntário ${ }^{43}$. O uso da prisão provisória como ameaça e a situação precária do sistema prisional bra-

41 A dúvida acerca da posição do juiz nos acordos como terceiro controlador é mencionada também por Greco, em seu prefácio à obra (DE-LORENZI, ob. cit. (nota 3), p. 8). 
sileiro consistiriam em fatores adicionais de coação ${ }^{44}$, argumento extremamente relevante.

Para o autor, ainda que o ordenamento preveja outras formas de tratamento mais leniente ao réu em função de seu comportamento posterior ao crime (arrependimento posterior, confissão, reparação do dano, colaboração premiada, transação penal, etc.), apenas no acordo sobre a sentença será possível a privação da liberdade (e sem instrução probatória). Por isso, no fenômeno do acordo sobre a sentença, a coação inerente à simples oferta de uma punição mais branda possuiria um potencial coativo maior do que nos demais institutos, motivo pelo qual a sua adoção deveria ser rechaçada pelo legislador brasileiro ${ }^{45}$.

No entanto, assumindo que o legislador venha a introduzir o acordo por aqui, o autor elenca algumas medidas que deveriam ser tomadas para minimizar o risco de coação nos acordos, como única forma de compatibilização do acordo com o princípio da culpabilidade, mas que demandariam verdadeiras alterações no sistema jurídico penal. Essas medidas passariam pelo estabelecimento de parâmetros moderados para a diminuição da pena, que poderiam ser extraídos da análise de proporções já adotadas pelo ordenamento brasileiro para a redução de pena por comportamentos pós-delitivos (confissão, arrependimento posterior, etc.) ou da análise do direito comparado ${ }^{46}$. Além disso, o autor defende ${ }^{47}$ : a) a vedação de acordos sobre fatos ou capitulações; b) a instauração de mecanismos de controle das negociações; c) a possibilidade de negociação somente após o recebimento da denúncia (após resposta do acusado); d) a exigência de exposição detalhada na denúncia sobre o fato criminoso, suas circunstâncias, classificação do crime, com tipo básico, qualificado e privilegiado, majorantes e minorantes, regras de concurso de crimes, agravantes e atenuantes; e) a atribuição da análise do acordo ao juiz da fase de instrução; f) a possibilidade de emendatio libelli no recebimento da peça acusatória; g) o estabelecimento na legislação da nulidade absoluta de qualquer acordo realizado antes do recebimento da denúncia; h) restrição das possibilidades de "punição pelo julgamento" ao imputado que se recuse a realizar o acordo; i) vedação à renúncia geral a qualquer tipo de recurso; j) a adoção de precauções acerca dos acordos firmados durante prisão provisória. 
As sugestões são importantes balizas para a superação de obstáculos impostos pela eventual adoção do acordo sobre a sentença no Brasil, mas não são soluções fechadas, como alerta o próprio autor ${ }^{48}$, devendo ser consideradas pelo Poder Legislativo e melhor desenvolvidas e testadas pela comunidade jurídica, avaliando sua compatibilidade com outros interesses também realizados no processo penal.

Para averiguar a compatibilidade do acordo sobre a sentença com as teorias das normas penais, o autor parte da classificação da norma penal como normas de valoração e normas de determinação, assumindo que a norma penal teria o papel de orientar o comportamento dos cidadãos ${ }^{49}$.

A partir das críticas de Schünemann e Herrera Guerrero ${ }^{50}$ ao acordo, por uma perspectiva de proteção de bens jurídicos por meio da prevenção geral negativa, a norma de conduta seria um imperativo de conduta, cujo descumprimento, por meio do acordo, distorceria a mensagem que as normas penais deveriam passar aos cidadãos e colocaria em risco o sistema jurídico penal ${ }^{51}$.

No entanto, para o autor, mesmo sob a perspectiva da norma de conduta como orientadora de comportamentos, com caráter dissuasório ${ }^{52}$, nem todas as infrações deveriam ser punidas, considerando a existência de outros valores e interesses igualmente relevantes ao direito penal e que, em alguns casos, a punição não produziria os efeitos esperados ${ }^{53}$.

A partir do papel da norma penal na prevenção geral como fomentadora de condutas e da gradação das sanções penais (medida e espécie) como expressão de diferenciação da gravidade entre condutas distintas, o autor passa a analisar os modelos de acordo sobre a sentença que se conhece: acordo sobre os fatos (fact bargaining), sobre a capitulação (charge bargaining) e sobre as penas (sentence bargaining).

O autor conclui que a negociação da capitulação jurídica extinguiria a distinção qualitativa e quantitativa entre os crimes traçada pelo legislador, o que afetaria a credibilidade do direito penal, e que a vítima possuiria uma pretensão legítima de ver o infrator condenado pelo crime praticado (embora questione a 
existência de uma pretensão à efetiva imposição ou quantificação da pena) ${ }^{54}$. Essa conclusão se estenderia às qualificadoras, aos privilégios, e às circunstâncias agravantes e atenuantes, já que alterariam igualmente a gravidade da proibição. Do mesmo modo, por afetar a mensagem da proibição, não se poderia admitir com o acordo a diminuição do número de imputações atribuídas ao sujeito ${ }^{55}$.

Igualmente, a possibilidade de negociar os fatos do processo seria vedada, já que a correta mensagem da proibição que foi violada dependeria do estabelecimento do fato que verdadeiramente ocorrera ${ }^{56}$, o que seria impossibilitado pela ausência de instrução.

Sobre a negociação das sanções, a redução de uma pena dependeria de uma justificação subjetiva das razões de sua não aplicação, em proporcionalidade com a gravidade do crime e a culpabilidade do agente. A isenção de uma pena só poderia ocorrer, excepcionalmente, quando a não punição tivesse a função de proteger interesses de grande valor. Para essa avaliação de oportunidade, o autor sugere que sejam adotadas as mesmas cautelas que elabora para o controle do risco de coação de inocentes, antes descritas ${ }^{57}$.

Por fim, com base ainda na valoração das diferentes condutas e na especial reprovação decorrente de alguns delitos, o autor sugere uma limitação ao acordo sobre a sentença com base no desvalor do crime, já que um acordo sobre alguns tipos de crimes seria socialmente injustificável e perturbaria a confiança no sistema jurídico penal. O autor observa, com razão, que tal diferenciação já é adotada pelo ordenamento jurídico (a exemplo de regras para fixação de regime de pena) e pelo texto constitucional, ao estabelecer hipóteses de imprescritibilidade e inafiançabilidade (art. 5ํㅜ XLII e XLIV, da CF) e de vedação a graça e anistia (art. 5은 XLIII, da CF $)^{58}$. Defende, portanto, a existência de um verdadeiro "âmbito nuclear de crimes inegociáveis" ${ }^{\prime 59}$, com a vedação do acordo a crimes cumulativamente: a) dolosos; b) contra a vida, integridade física e liberdade/dignidade sexual ou mediante violência ou grave ameaça, com um filtro adicional; c) punidos com reclusão ${ }^{60}$. 
Ao fim de seu estudo, De-Lorenzi testa a compatibilidade do acordo sobre a sentença com as principais teorias da pena, a retribuição, a prevenção geral, a prevenção especial e as teorias expressivas, sem adentrar nas inúmeras críticas doutrinárias que cercam tais teorias.

O autor diferencia as teorias absolutas e relativas da retribuição, a partir das perspectivas de Kant e Hegel ${ }^{61}$. As absolutas, por exigirem a punição de todo e qualquer crime, como um imperativo categórico, não deixariam qualquer espaço para acordos processuais, admitindo a redução da pena apenas por comportamentos posteriores ao crime, a partir de um valor moral, como arrependimento ou remorso do acusado, e não por mera conveniência ${ }^{62}$. Já as teorias relativas, mais modernas, por admitirem a culpabilidade como pressuposto da punição, mas não como dever de punir, admitiriam, em tese, a abdicação da pena por razões preventivas $^{63}$, desde que com fundamentado jurídico-constitucional. Na prática, pela exigência desse fundamento legitimador, que não poderia ser de cunho meramente consequencialista, a compatibilidade das teorias retributivas com o acordo sobre a sentença, mesmo as relativas, também enfrentaria dificuldades ${ }^{64}$.

Sob a perspectiva da prevenção geral negativa, que evita crimes futuros a partir do efeito dissuasório da imposição da pena sobre a população, a proporcionalidade da punição não seria um fim em si mesmo, mas instrumento de prevenção de crimes, que poderia ceder espaço a uma pena desproporcional que evitasse melhor o cometimento de crimes ${ }^{65}$. Nesse ponto, o autor tece considerações sobre os fatores que melhor desestimulariam a prática de crimes, se a severidade da punição ou a certeza da punição. Admitindo-se a prevalência da certeza da punição, a existência do acordo sobre a sentença seria justificável, já que um sistema com menos impunidade teria maior eficácia dissuasória ${ }^{66}$. Entretanto, o autor alerta, com razão, que o efeito dissuasório resultante do aumento da probabilidade e da celeridade da punição com o acordo só seria admissível caso não afetasse a percepção geral da população sobre a seriedade da punição, exigindo-se uma redução de pena limitada, que não descaracterizasse a ameaça ${ }^{67}$.

62 DE-LORENZI, ob. cit. (nota 3), p. 297.

63 DE-LORENZI, ob. cit. (nota 3), p. 294 e 295.

64 DE-LORENZI, ob. cit. (nota 3), p. 295.

65 DE-LORENZI, ob. cit. (nota 3), p. 299.

66 DE-LORENZI, ob. cit. (nota 3), p. 301.

67 DE-LORENZI, ob. cit. (nota 3), p. 302. 
Já, a partir da prevenção geral positiva, centrada na reafirmação e credibilidade do ordenamento jurídico, a imposição de uma pena a um certo comportamento comunicaria o seu desvalor. Para a compreensão do desvalor comunicado, o autor traça a distinção entre uma posição moralista ou pedagógica, uma posição jurídico-formal, positivista ou sistêmica, e a concepção jurídico material ou integradora, concluindo que todas as concepções entenderiam a imposição da pena como reafirmação da norma ${ }^{68}$, sendo razoável imaginar uma necessária relação de proporcionalidade entre a pena aplicada e o ilícito cometido, de forma a expressar a importância da norma descumprida ${ }^{69}$ e comunicar o desvalor da conduta. Nesse sentido, do ponto de vista da prevenção geral positiva, a justiça negociada poderia ser justificada pela comunicação à sociedade da vantagem de persecução e punição de crimes que não seriam punidos de outro modo, desde que não levasse a uma tal redução de pena que descaracterizasse a expressão de desvalor da norma violada. Da mesma forma, pela prevenção geral positiva, a possibilidade de negociação acerca de crimes graves dificilmente seria justificada. Para o autor, um modelo que restrinja o âmbito do acordo, limitando as reduções de pena a quantias moderadas e proporcionais ao ilícito e à culpabilidade, justificadas por efeitos benéficos ao funcionamento do sistema penal, seria compatível com os fins da prevenção geral positiva ${ }^{70}$.

O autor trata ainda da prevenção especial, positiva e negativa, focada no indivíduo infrator, admitindo a versão moderna da teoria, mais compatível com um Estado liberal, focada na evitação de reincidência futura por meio de oportunidades de reinserção social e incentivos e na evitação da pena de prisão ${ }^{71}$. Sob essa perspectiva, a compatibilidade do acordo sobre a sentença dependeria do seu papel na evitação de novos crimes pelo condenado e passaria pela forma que a regulamentação adquiriria no Brasil, já que não se poderia imaginar a assunção de responsabilidade ou o reconhecimento do erro cometido, pelo acusado, em um sistema que admitisse acordos sobre fatos e crimes, o que não necessariamente ocorreria em um modelo de acordo sobre a pena que possibilite sua disposição moderada e conforme os marcos legais ${ }^{72}$. O autor considera, ainda, que as finalidades preventivo-especiais seriam mais bem alcançadas pela utilização de "técnicas de diversão", já conhecidas pelo ordenamento brasileiro (como a suspensão 
condicional do processo), que estabelecem condições ao réu, por um período de prova, cujo descumprimento levaria ao prosseguimento do processo, com possibilidade de condenação. Sob a concepção de prevenção especial enquanto "maximação de não dessocialização", que busca evitar a imposição de pena privativa de liberdade, a criação de acordos sobre a sentença não teria, segundo o autor, grande relevância para o ordenamento brasileiro, que já prevê o uso de medidas alternativas à prisão para crimes de média e alta gravidades ${ }^{73}$.

Por fim, o autor analisa brevemente a compatibilidade do acordo sobre a sentença com as chamadas teorias expressivas, que não buscariam justiça mediante reação proporcional e nem a evitação de crimes futuros, vendo uma função comunicativa nas sentenças penais. Tais teorias não seriam incompatíveis com o acordo, mas exigiriam a vedação de negociação sobre os fatos e as capitulações legais (que traria danos à dimensão comunicativa da pena) e trariam algumas exigências adicionais ao procedimento do acordo ${ }^{74}$.

As reflexões supra são extremamente válidas para o Brasil, considerando a compreensão majoritária sobre a adoção de uma teoria eclética pelo ordenamento pátrio, que agregaria as finalidades de retribuição e prevenção (geral e especial) da pena, fundamentada pela doutrina, especialmente no art. 59 do CP e arts. $2^{\circ}$ e 10 da LEP ${ }^{75}$. De-Lorenzi conclui que, como a prevenção geral (positiva ou negativa) é finalidade da pena reconhecida no Brasil, a possibilidade de os acordos sobre a sentença reduzirem a punição, desde que moderadamente, não vedaria, a princípio, a adoção do acordo pelo ordenamento brasileiro ${ }^{76}$.

A despeito de se posicionar contrariamente à adoção dos acordos sobre a sentença no Brasil, assumindo a hipótese de sua internalização, o autor traça, ao final da obra, uma interessante proposta de modelo de redução da pena pelo acordo, que respeitaria as implicações impostas pela legalidade, pela culpabilidade e pelas teorias das normas e das penas aos acordos ${ }^{77}$.

Nesse sentido, partindo da premissa de que as partes não deveriam ter liberdade irrestrita sobre o acordo, que só poderia ocorrer sobre a pena, e não sobre fatos e capitulações, o autor defende que a lei deveria fixar expressamente como e quanto a pena deveria ser reduzida e que essa redução deveria se dar na 
terceira fase de aplicação da pena, por uma minorante especial ${ }^{78}$. Isso manteria os marcos penais inalterados, respeitando a mensagem transmitida pela norma de conduta, bem como garantiria transparência às etapas de aplicação da pena, visualizando facilmente o quantum de redução que ela teve em função do acordo. Para minimizar os riscos de insegurança do acusado, decorrentes da redução da pena somente ao final das etapas, o autor propõe a fixação expressa na legislação de uma fração determinada de redução da pena.

A partir de uma análise dos marcos de redução já adotados pelo ordenamento brasileiro nos chamados comportamentos pós-delitivos positivos fundados em fatores objetivos, como a colaboração premiada, a reparação do dano (art. 65, III, b, do CP), a confissão (art. 65, III, d, do CP) e o arrependimento posterior (art. 16 do CP), o autor conclui que a redução não deva ser superior a $1 / 3$ e nem inferior a 1/6 da pena, sob pena de desestimular a realização do acordo. Essa conclusão é corroborada pela investigação, pelo autor, dos acordos na Alemanha, Itália e Espanha, que adotam patamares de redução entre 1/3 e 1/4 da pena. Assim, sugere, com razoabilidade, a redução da pena pelos acordos entre $1 / 5$ e $1 / 3$ da pena ${ }^{79}$.

Acerca de outros conteúdos passíveis de negociação por acordo, o autor se posiciona, brevemente, contrário à negociação sobre o regime de cumprimento de pena ou benefícios na execução da pena, que acarretariam uma pressão inadmissível sobre o acusado para aceitação da condenação ${ }^{80}$. Lado outro, posiciona-se favoravelmente à possibilidade de negociação em acordo sobre os efeitos específicos da sentença, que não são automáticos (art. 92, parágrafo único, do CP) e possuiriam margem de discricionariedade. Por fim, entende impossível o acordo sobre medidas de segurança, já que essas não impõem condenação ou análise da culpabilidade, mas de periculosidade do agente, devendo ser fixadas, em tese, já no mínimo necessário aos fins preventivo-especiais, o que não deixaria espaço para negociação de pena. Ademais, por implicarem no reconhecimento da inimputabilidade do agente, as medidas de segurança seriam incompatíveis com a exigência de consciência e voluntariedade ${ }^{81}$.

Por tudo aqui exposto, com as limitações naturais de uma resenha, recomenda-se veementemente a leitura da obra de De-Lorenzi. A estruturação ori- 
ginal que o autor faz sobre o assunto, a profunda pesquisa realizada e os argumentos bem desenvolvidos tornam sua obra uma grande e sólida contribuição ao tema dos acordos sobre a sentença no Brasil. Some-se a isso o fato de o autor, apesar de sua clara posição contrária à assimilação do instituto no País, oferecer interessantes soluções e linhas mestras para diminuir os impactos decorrentes de uma eventual internalização do acordo por aqui, que podem e devem guiar um aprofundamento do debate sobre o tema.

Sobre a autora:

Ana Claudia Grossi | E-mail: anaclaudiagrossi@yahoo.com.br

Mestre (LL.M) em Direito (LMU-München/Alemanha). Advogada.

Recebimento: 03.11.2021

Aprovação: 07.11.2021 